\title{
Investigation of the Effect of 8-Week Reformer Pilates Exercise on Flexibility, Heart Rate and Glucose Levels in Sedentary Women
}

\author{
Gürhan Suna ${ }^{1}$ \\ Kenan Ișildak ${ }^{2}$
}

1,2Department of Coaching Education, Süleyman Demirel University, Isparta, Turkey.

Email. gürhan suna@windoruslive.com Tel: +905533850104

Email.kenanisildak@hotmail.com Tel: +905313020418

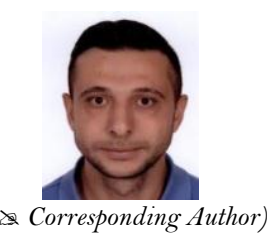

\section{Abstract}

The aim of this study is to investigate the effects of reformer pilates exercises on flexibility, heart rate and glucose levels of sedentary women for 8 weeks. 30 sedentary women between 30-36 years old were joined to the study. Participated in the research sedentary women' ages' mean was $32,20 \pm 1,78$ year, lenghts' mean was $166,76 \pm 3,93 \mathrm{~cm}$. It is announced to the participants that personal information and findings obtained during and after the research will be kept strictly confidential and also "Informed Voluntary Consent Form" was filled up. Reformer pilates exercise was performed regularly for 8 weeks, \%40-60 loading intensity, 3 days a week, 60 minutes per day. Measurements were obtained as pre-test and post-test. SPSS programme was used. "Paired $t$ test" was used to determine the difference before and after exercise. The results were evaluated at $\mathrm{p}<0,05$ significance level. The comparison of body weight, resting-maximum heart rate, flexibility and glucose 1. day and 8 . week post- exercise measurements were statistically significant $(p<0,05)$. But there were no significant different in glucose 1 . day and 8 . week pre- exercise measurements $(p>0,05)$. As a result of our study based on the data obtained, it was determined that regular reformer pilates exercises accelerated weight loss on sedentary women. In addition, it had positive effects on flexibility, heart rate and glucose measurements.

Keywords: Reformer pilates, Exercise, Sedentary women, Heart rate, Glucose, Flexibility.

Citation | Gürhan Suna; Kenan Iş̧ldak (2020). Investigation of the Effect of 8 -Week Reformer Pilates Exercise on Flexibility, Heart Rate and Glucose Levels in Sedentary Women. Asian Journal of Education and Training, 6(2): 226-230.

History:

Received: 8 January 2020

Revised: 19 February 2020

Accepted: 23 March 2020

Published: 13 April 2020

Licensed: This work is licensed under a Creative Commons

Attribution 3.0 License (oc)

Publisher: Asian Online Journal Publishing Group
Acknowledgement: Both authors contributed to the conception and design of the study.

Funding: This study received no specific financial support.

Competing Interests: The authors declare that they have no conflict of interests.

Transparency: The authors confirm that the manuscript is an honest, accurate, and transparent account of the study was reported; that no vital features of the study have been omitted; and that any discrepancies from the features of the study have been omitted
study as planned have been explained.

Ethical: This study follows all ethical practices during writing.

\section{Contents}

1. Introduction.

2. Material and Method.

References. 


\section{Contribution of this paper to the literature}

This study contributes to the literature in terms of monitoring the progress both by themselves and their trainers and improving the quality of life by seeing the physical and physiological changes of the reformer pilates, which has become a popular, exercise recently, in sedentary women.

\section{Introduction}

The idea of the design of the reformer was laid by Joseph Pilates in an attempt to self-treat the beds of soldiers wounded during the First World War. It can be said that Joseph Pilates's treatment of patients with springs attached to beds and walls in the hospital is in fact the first days of the foundation of modern Reformer tools. The main purpose of exercising on the reformer is to strengthen the body as well as to give the body the right flexibility within the framework of its current potential, to correct posture disorders and to keep proper breathing control during all these practices and to stick to the principles of smooth movement at an appropriate pace (Bullo et al., 2015; Rodrigues, Cader, Torres, de Oliveira, \& Dantas, 2009; Sekendiz, Altun, Korkusuz, \& Akın, 2006; Tamer, 1995).

Another reason why reformer pilates exercises have been popular for years is that they work against the springs, not against gravity. In a study, it was emphasized that gravity provides a constant external resistance to the angle of movement in exercise, while the springs provide an increased external resistance while the muscles extend (Siler, 2000).

In Pilates, the anatomical structure and muscles of the participant, structurally considered as a whole. In addition to reducing the risk of injury, Pilates increases endurance and metabolic rate of participants (Kılıç, Uğurlu, $\&$ Dikdağ, 2018).With the help of equipment used in pilates exercises, it is necessary to create posture correcting and balancing positions and movements in order to improve the participant's whole body. Pilates exercise, from the initial stage to the mastery stage, is a wide range of various exercises can be performed by using some devices and apparatus. Stretchs with different resistance levels, pulleys, and gravity-driven equipment, affect the muscle structure of the participants from various angles. It helps to focus especially on the internal muscular system. By working the deep layers of the muscles, the correct position, posture and optimum movement capacity is tried to be obtained (Isacowitz \& Clippinger, 2001).

Although Pilates is a less severe exercise than other aerobic and dance exercises, it is a very important type of exercise for a healthy body with concentration, control, centering, flowing movement rhythm, precision of movement and breathing technique during the exercise. Some studies have shown that pilates exercises reduce the risk of heart disease, prevent osteoporosis, shape the body, improve balance, flexibility and strength (Robinson \& Hunter, 2003; Schroeder, Crussemeyer, \& Newton, 2002; Segal, Hein, \& Basford, 2004). With Pilates exercises, muscle flexibility is increased (Otto et al., 2004; KV. Rogers \& Gibson, 2006; Schroeder et al., 2002; Segal et al., 2004) compression forces on articular and pelvic tilt are reduced, spine stability and posture disorders corrected (McMillan, Proteau, \& Lèbe, 1998). Furthermore, it is stated that body awareness is improved with these exercises, there are decreases in low back pain (Anderson \& Spector, 2009) and increases in bone density (Betz, 2005). In addition to the mentioned benefit, the positive effects of pilates exercises on strength, posture, flexibility, basal metabolism, lean mass and general body values have been examined and proven in many studies (Bernardo, 2007; Cakmakçi, 2011; de Souza \& Vieira, 2006).

The aim of this study is to investigate the effects of reformer pilates exercises on flexibility, heart rate and glucose of sedentary women for 8 weeks.

\section{Material and Method}

\subsection{Participants}

Thirty sedentary women, between 30-36 years old participated in the study. It is announced to the participants that personal information and findings obtained during and after the research will be kept strictly confidential and also "Informed Voluntary Consent Form" was filled up. According to the information given, the research group was asked not to engage in any strenuous physical activity before the tests. Reformer pilates exercise with instruments was performed regularly for 8 weeks, 3 days a week, 60 minutes per day.

\subsection{Measures}

\subsubsection{Measurement of Height}

The height of the athletes was measured by using a SECA brand height scale having an accuracy of $0.01 \mathrm{~mm}$ sensitivity. The values were recorded as "cm".

\subsubsection{Measurement of Body Weight}

The body weight of the athletes was measured by using a SECA brand weight scale having an accuracy of $0.001 \mathrm{~kg}$ sensitivity. The values were recorded as "kg".

\subsubsection{Measurement of Heart Rate}

Heart Rate with Nimo brand pulse meter, before and after exercise measurements were taken.

\subsubsection{Measurement of Blood Glucose}

OKmeter Optima OK-10H (Taiwan) glucose meter was used in the measurement of blood glucose values of the research group. Glucose measurement was recorded before and after the test.

\subsubsection{Measurement of Flexibility}

The flexibility of the athletes was measured by a sit and lie test on the flexibility table. The athletes were taken to this test after warming up for five minutes. Stretching distance was recorded as the athletes, with their naked soles, sitting on the floor, leaning forward on the test stand, reaching forward without bending their knees, 
pushing the ruler on the stand forward, and stretching for 2 seconds at the furthest point on which they lie. The athletes repeated the test three times, and the maximum value that they took was recorded in $\mathrm{cm}$.

\subsubsection{Exercise Program}

Reformer pilates exercise program was used for all muscle groups. Reformer exercises include Kneeling arms, Double Leg Press Plantar Flexed, Standing Series, Chest fly, Feet in starps, Single Leg Press Series, Squat spinning movements. Exercises, the movement is made to be fluent in the transition. Each movement was performed \%40-60 of maximal heart rate in loading intensity, 3 sets, with 12 repetitions and yielding rest. Before and after the exercises, stretching movements were performed for 15-20 minutes for the purpose of warmingcooling.

\subsubsection{Data Analysis}

In the study, the data were analyzed by using statistical package program. Descriptive statistics were used for mean and standard deviation values, "Shapiro-Wilk" test was used to determine whether the data showed normal distribution or not and determining whether there is a difference before and after exercise, "Paired $t$ Test" was analyzed. The results were evaluated according to " $\mathrm{p}<0,05$ " significance level.

\section{Findings}

Table-1. Physical information of training groups participating to research.

\begin{tabular}{c|c|c|c|c}
\hline Parameters & $\mathbf{N}$ & Minimum & Maximum & Mean \pm Sd \\
\cline { 1 - 4 } Age (year) & \multirow{2}{*}{30} & 30,00 & 36,00 & $32,20 \pm 1,78$ \\
\cline { 1 - 3 } Height $(\mathrm{cm})$ & & 160,00 & 175,00 & $166,76 \pm 3,93$ \\
\hline Note: ${ }^{p}<0,05$. & &
\end{tabular}

As shown in Table 1, the mean age of the participants was 32,20 \pm 1,78 years and the mean height was 166,76 $\pm 3,93$ years.

Table-2. Comparison of body weight pre and post-test measurements of participants.

\begin{tabular}{c|c|c|c|c}
\hline Parameters & Tests & Mean \pm Sd & t & p \\
\hline \multirow{2}{*}{ Body Weight $(\mathrm{kg})$} & 1. Day Pre-Exercise & $63,43 \pm 7,46$ & & \multirow{2}{*}{4,147} \\
\cline { 2 - 3 } & 8. Week Post- Exercise & $61,8 \pm 7,000^{*}$ & & \\
\hline Note: ${ }^{*} \mathrm{p}<0,05$.
\end{tabular}

According to the Table 2, a significant decrease was found in body weight values of women who participated in the study as a result of comparison of pre-test and post-test averages $(p<0,05)$.

Table-3. Comparison of heart rate pre and post-test measurements of participants

\begin{tabular}{l|l|c|c|c}
\hline Parameters & Tests & Mean \pm Sd & $\mathbf{t}$ & $\mathbf{p}$ \\
\hline \multirow{2}{*}{ Resting Heart Rate (beat/min) } & 1. Day Pre- Exercise & $86,53 \pm 8,40$ & \multirow{2}{*}{2,43} & \multirow{2}{*}{, $021^{*}$} \\
\cline { 2 - 3 } & 8. Week Pre- Exercise & $85,50 \pm 8,32$ & \multirow{2}{*}{2,79} & \multirow{2}{*}{, $009^{*}$} \\
\hline \multirow{2}{*}{ Maximum Heart Rate (beat/min) } & 1. Day Post- Exercise & $112,70 \pm 12,83$ & $109,50 \pm 12,86$ & \\
\cline { 2 - 3 } & 8. Week Post- Exercise & Note ${ }^{*}<0,05$.
\end{tabular}

As shown in Table 3, statistically significant difference was found between the rest and maximum pulse values of the participants before and after exercise $(\mathrm{p}<0,05)$.

Table-4. Comparison of glucose pre and post-test measurements of participants.

\begin{tabular}{|c|c|c|c|c|}
\hline Parameters & Tests & Mean \pm Sd & $\mathrm{t}$ & $\bar{p}$ \\
\hline \multirow{4}{*}{ Glucose $(\mathrm{mg} / \mathrm{dl})$} & 1. Day Pre- Exercise & $92,36 \pm 14,23$ & \multirow[b]{2}{*}{,- 151} & \multirow{2}{*}{, 881} \\
\hline & 8. Week Pre- Exercise & $92,50 \pm 12,65$ & & \\
\hline & 1. Day Post- Exercise & $92,10 \pm 11,89$ & \multirow{2}{*}{2,942} & \multirow{2}{*}{,006* } \\
\hline & 8. Week Post- Exercise & $90,76 \pm 11,90$ & & \\
\hline
\end{tabular}

When examined in Table 4, there was no statistically significant difference between the 1. day and 8 . weeks before exercise ( $p>0,05)$; It was found to be significant after 1. day and 8 . weeks after exercise $(p<0,05)$.

Table-5. Comparison of flexibility pre and post-test measurements of participants.

\begin{tabular}{c|l|l|l|c}
\hline Parameters & Tests & Mean \pm Sd & t & p \\
\hline \multirow{2}{*}{ Flexibility $(\mathrm{cm})$} & 1. Day Pre- Exercise & $24,70 \pm 7,96$ & \multirow{2}{*}{, $000 *$} \\
\cline { 2 - 3 } & 8. Week Post- Exercise & $26,50 \pm 8,36$ & \\
\hline
\end{tabular}

According to the Table 5, a statistically significant difference was found between the flexibility measurement values of the participants before and after exercise $(p<0,05)$.

\section{Conclusion}

As a result of the 8-week reformer pilates exercises applied to sedentary women, it was determined that reformer pilates exercise positively caused physical and physiological differences. In our study, the comparison of body weight, resting-maximum heart rate, flexibility and glucose 1. day and 8. week post- exercise measurements 
were statistically significant $(\mathrm{p}<0,05)$. But there were no significant different in glucose 1 . day and 8 . week preexercise measurements $(p>0,05)$. We think that the reason for the development of is the effect of the reformer pilates exercises.

Kurşun, Suna, and Alp (2016) examined the effect of 12-week regular step aerobic exercises on body fat values in adult sedentary women found that although there was a decrease in body weight values, it did not cause a statistically significant change. This study is similar to our study in terms of reduction in body weight.

In a similar survey conducted with 47 adult individuals, it is presented that, when the pilates exercises applied regularly (at least 1 hour per week), it improved the flexibility values (2nd month: $3.4 \mathrm{~cm}(1.3-5.7 \mathrm{~cm}), 4$ th month: $3.3 \mathrm{~cm}(0.3-7.8 \mathrm{~cm})$ and 6 th month: $4.3 \mathrm{~cm}(1.5-7.6 \mathrm{~cm})$. When these studies were compared, it was found that flexibility values are increased (Segal et al., 2004). While the arithmetic mean of the pre-exercise flexibility values of the experimental group was $31.30 \pm 7.18$, this value was found to be $35.90 \pm 5.74$ after the exercise (Kılıç et al., 2018). $4.60 \mathrm{~cm}$ increase between pre- and post-exercise values was found to be statistically significant $(\mathrm{p}<0,01)$. Turna and Alp (2020) also reported in their study that trainings had positive effects on flexibility of participants. Altıntaç (2006) after exercising pilates with women over the age of 30, he looked at the flexibility values in flexibility measurements. As a result of these measurements, statistically significant differences were found. Kate Rogers and Gibson (2009) reported that regular pilates studies in middle-aged sedentary women have significant effects on muscle endurance, body composition and flexibility. Otto et al. (2004) also supported the positive effects of pilates exercise method on flexibility values. In this reformer study, it was reported that the flexibility values of the group performing the reformer exercises were significantly different from the group performing the resistance exercises. Babayiğit (2009) study showed that the 12-week, 3-day per week, and 1-hour per day pilates exercise program increased the flexibility values of the women participating in the study. This development shows that Pilates exercises have significant effects on improving flexibility values. Cağlav (2005) on the other hand, found significant differences in flexibility measurements after pilates exercise performed by women aged $40-45$ years. This study is in line with the studies in literature. We can say that the increase in flexibility values of women is beneficial on flexibility feature of doing Pilates exercise.

In a study conducted by Rico-Sanz, Zehnder, Buchli, Dambach, and Boutellier (1990) blood glucose levels were $87 \pm 2.7 \mathrm{mg} / \mathrm{dl}$ at before and $42 \pm 2.5 \mathrm{mg} / \mathrm{dl}$ at after. When exercise is severe and prolonged, it is seen that blood glucose also falls below normal resting levels due to decreased liver glycogen. In a study by Cox et al. (2001) on sedentary women aged 40-65 years, the effect of exercise on blood pressure was examined. At the end of 60 exercises of 18 months, systolic and diastolic blood pressures of the subjects were decreased. Colakoğlu and Senel (2003) examined the effect of 8-week aerobic exercise program on some physical parameters in middle-aged women and found a significant decrease in resting pulses of 9.2 beats / min between experimental subjects.

Erbas (2007) examined the effect of aerobic exercise program on physical and physiological parameters in middle-aged sedentary women. He took three measurements, before, in the middle and at the end of the exercise, and found a significant reduction in resting pulse rates.

Velasques and Wilmore (1991) investigated changes in body composition and cardiorespiratory fitness after a 12-week step study in women aged 18-33 years. At the end of the study, it was observed that the resting heart rate decreased. When the results in the literature are examined, we believe that the data in our study support the results.

Çolakoğlu and Karacan (2006) applied aerobic exercises in their research and they observed reductions in the number of resting heart rate after exercise. The results of this study support our results.

As a result, based on the data obtained from our study, we can say that there are positive changes in physical and physiological characteristics of regular reformer pilates exercises performed on sedentary women. For the continuation of these changes and for an ideal body structure and health, we can say that these and similar exercises should be done regularly. In addition, we think that these kinds of exercises can overcome many health problems that may arise in the elderly ages. In addition to exercises done for health and physical fitness, people may also be advised to check their nutritional habits before and after exercise and also they may be advised to exercise with the help of an experts.

\section{References}

Altıntaç, D. (2006). Effects of Pilates exercises on physical fitness. Marmara University Institute of Health Sciences Physical Education and Sports Department Master Thesis. Istanbul: Marmara University.

Anderson, B. D., \& Spector, A. (2009). Introduction to Pilates-based rehabilitation. Orthopaedic Physical Therapy Clinics of North America, 9(3), 395-410.

Babayiğit, I. G. (2009). Pilates exercise positively affects balance, reaction time, muscle strength, falling number and psychological parameters in older women over 65 years of age. Middle East Technical University Institute of Social Sciences Physical Education and Sports Department, Ph.D. Thesis, Ankara: METU.

Bernardo, L. M. (2007). The effectiveness of Pilates training in healthy adults: An appraisal of the research literature. Journal of Bodywork and Movement Therapies, $11(2)$, 106-110.Available at: https://doi.org/10.1016/j.jbmt.2006.08.006.

Betz, S. (2005). Modifying pilates for clients with osteoporosis. IDEA Fitness Journall, 2(4), 46-55.

Bullo, V., Bergamin, M., Gobbo, S., Sieverdes, J., Zaccaria, M., Neunhaeuserer, D., \& Ermolao, A. (2015). The effects of pilates exercise training on physical fitness and wellbeing in the elderly: A systematic review for future exercise prescription. Preventive Medicine, 75, 1-11.Available at: https://doi.org/10.1016/j.ypmed.2015.03.002.

Cağlav, F. (2005). Effects of 8-week pilates study on flexibility and balance in women between the ages of 40-45. Mugla University Institute of Social Sciences Physical Education and Sports Department Master Thesis, Mugla: Mugla University.

Cakmakçi, O. (2011). The effect of 8 week plates exercise on body composition in obese women. Collegium Antropologicum, 35(4), 1045-1050.

Colakoğlu, F., \& Senel, Ö. (2003). Effects of the eight-week aerobic exercise program on the body composition and blood lipids of sedentary middle-aged women. SPORMETER 1(1), 57-61.

Çolakoğlu, F. F., \& Karacan, S. (2006). The effect of aerobic exercise on some physiological parameters in young women and middle-aged women. Kastamonu Education Journal, 14(1), 277-284.

Cox, K. L., Burke, V., Morton, A. R., Gillam, H. F., Beilin, L. J., \& Puddey, I. B. (2001). Long-term effects of exercise on blood pressure and lipids in healthy women aged 40-65 years: The Sedentary Women Exercise Adherence Trial (SWEAT). Journal of Hypertension, 19(10), 1733-1743.Available at: https://doi.org/10.1097/00004872-200110000-00006.

de Souza, M. V. S., \& Vieira, C. B. (2006). Who are the people looking for the Pilates method? Journal of Bodywork and Movement Therapies, $10(4)$, 328-334.Available at: https://doi.org/10.1016/j.jbmt.2005.10.005. 
Erbas, U. (2007). Physical and physiological effects of calisthenic exercises for middle-aged obese women. Gazi University, Institute of Health Sciences, Department of Physical Education and Sports, M.Sc. Thesis, Ankara: Gazi University.

Isacowitz, R., \& Clippinger, K. (2001). Balanced body universt. Human Kinetics, 17, 55-27.

Kılıç, T., Uğurlu, A., \& Dikdağ, M. (2018). Reformer pilates in middle age sedentary women; Examination of the effects on body weight, body fat percentage and flexibility. SPORMETRE Journal of Physical Education and Sports Sciences, 16(2), 153-161.

Kurşun, Ş., Suna, G., \& Alp, M. (2016). The effects of regular step-aerobic exercises on body fat values of adult sedentary women The effect of regular step-aerobic exercises on body fat values in adult sedentary women. Journal of Human Sciences, 13(3), 49734979.Available at: https://doi.org/10.14687/jhs.v13i3.4018.

McMillan, A., Proteau, L., \& Lèbe, R.-M. (1998). The effect of pilates-based training on dancers' dynamic posture. Journal of Dance Medicine E Science, 2(3), 101-107.

Otto, R., Yoke, M., McLaughlin, K., Morrill, J., Viola, A., Lail, A., ... Wygand, J. (2004). The effect of twelve weeks of Pilates vs resistance training on trained females. Medicine \& Science in Sports \& Exercise, 36(5), S356-S357.

Rico-Sanz, J., Zehnder, M., Buchli, R., Dambach, M., \& Boutellier, U. (1990). Muscle glycogen, depletion during sumulation of a fatiquing soccer match in elite soccer players examined noninvasively by 13C-MRS. Medicine Sci.Sports Exercise, 31(11), 1587-1593.

Robinson, L., \& Hunter, F. (2003). Pilates plus diet (1st ed.). London: Pan Books.

Rodrigues, d. S. B. G., Cader, S. A., Torres, N. V. O. B., de Oliveira, E. M., \& Dantas, E. H. M. (2009). Pilates method in personal autonomy, static balance and quality of life of elderly females. Journal of Bodywork and Movement Therapies, 14(2), 195-202.

Rogers, K., \& Gibson, A. (2006). Effects of an 8-week mat pilates training program on body composition, flexibility, and muscular endurance. Medicine $\mathcal{E}^{\circ}$ Science in Sports $\mathcal{E}^{\circ}$ Exercise, 38(5), 356-357.

Rogers, K., \& Gibson, A. L. (2009). Eight-week traditional mat Pilates training-program effects on adult fitness characteristics. Research quarterly for Exercise and Sport, 80(3), 569-574.Available at: https://doi.org/10.1080/02701367.2009.10599595.

Schroeder, J. M., Crussemeyer, J. A., \& Newton, S. J. (2002). Flexibilty and heart rate response to an acute Pilates reformer session. Medicine \& Science in Sports \& Exercise, 34(5), S258.Available at: https://doi.org/10.1097/00005768-200205001-01443.

Segal, N. A., Hein, J., \& Basford, J. R. (2004). The effects of Pilates training on flexibility and body composition: An observational study. Archives of Physical Medicine and Rehabilitation, 85(12), 1977-1981.

Sekendiz, B., Altun, O., Korkusuz, F., \& Akın, S. (2006). Effects of pilates exercise on trunk strength, endurance and flexibility in sedentary adult females. Journal of Bodywork and Movement Therapies, $11(4), 318-326$.

Siler, B. (2000). The pilates body. New York: Random House.

Tamer, K. (1995). Measurement and evaluation of physical physiological performance in sports (1st ed.). Ankara: Türkerler Bookstore.

Turna, B., \& Alp, M. (2020). The effects of functional training on some biomotor abilities and physiological characteristics in elite soccer players. Journal of Education and Learning, 9(1), 164-171.

Velasques, K., \& Wilmore, J. (1991). Changes in cardiorespiratory fitnes and body composition after a 12 week bench step training program. Medicine and Science in Sports and Exercise, 24(5 Supplement), 78. 